\title{
Association between hyperhomocysteinemia and adverse obstetric outcome in patients with bad obstetric history
}

\author{
Saswati Sanyal Choudhury, Lokeshwari K, Gokul Chandra Das \\ Corresponding author: Dr. Saswati Sanyal Choudhury, Professor, Department of Obstetrics and \\ Gynaecology, Gauhati Medical College. Guwahati, Assam, India; \\ Email : saswatisc@rediffmail.com
}

Distributed under Attribution-Non Commercial - Share Alike 4.0 International (CC BY-NC-SA 4.0)

\section{ABSTRACT}

\begin{abstract}
Background: Hyperhomocysteinemia is a condition characterized by an abnormally high level of homocysteine in the blood conventionally described above $15 \mu \mathrm{mol} / 1$. Plasma homocysteine concentrations are frequently found to be elevated in cases of bad obstetric history but a causal relationship between these two has not been clearly demonstrated yet. Objectives: The study was taken up with the objectives of determining the correlation between plasma homocysteine level and bad obstetric history, and its relevance as a potential marker for predicting bad obstetric outcome. Method: A total sixty five cases were taken. Out of which 45 cases had bad obstetric history and 20 had normal pregnancy in a tertiary care hospital from August, 2012 to July, 2013. It was a prospective observational study. Serum homocysteine level was measured by enzyme cycling method. Statistical tests used are Fisher test, Chi square test, student $\mathrm{T}$ test and ANOVA test to determine meaningful statistical outcome. Results: Mean serum homocysteine level in control group was $9.23 \pm 3.4 \mu \mathrm{mol} / 1$ and that of in bad obstetrical history (BOH) was $26.6 \pm 5.9 \mu \mathrm{mol} / 1(\mathrm{p}<0.001)$. BOH group with diagnosed preeclampsia had elevated homocysteine level. There was highly significant difference in mild and severe preeclampsia, $25.6 \mu \mathrm{mol} / 1 \mathrm{vs}$. $29.9 \mu \mathrm{mol} / 1(\mathrm{p}<0.001)$ and patients without hypertension with mild and severe disease $(\mathrm{p}<0.001)$. There was a relationship between level of homocysteine with adverse perinatal outcome like preterm and stillbirth (ANOVA test $\mathrm{P}<0.05$ ). Level of homocysteine was high in BOH with FGR $(p<0.05)$. Conclusion: High level of serum homocysteine has a strong association with bad obstetric outcome.
\end{abstract}

Keywords: Hyperhomocysteinemia, bad obstetric outcome, preeclampsia, adverse perinatal outcome, $\mathrm{BOH}, \mathrm{FGR}$

The term "BAD OBSTETRIC HISTORY" is applied to a pregnant mother, where present obstetric outcome is likely to be affected adversely by the nature of previous obstetric disaster ${ }^{1}$. Bad obstetric history implies previous unfavorable fetal outcome in terms of two or more consecutive spontaneous abortion, early neonatal death, still birth, intrauterine fetal death, fetal growth restriction and congenital anomalies.

Homocysteine is naturally occurring sulphur containing amino acid and results from the demethylation of essential amino acid methionine. Fifty percent is re-methylated back into methionine. Other fifty percent is transulfurated to cystathionine, a source of cysteine. Normal value of homocysteine is $5-15 \mu \mathrm{mol} / 1$ with accepted mean value of $9 \mu \mathrm{mol} / \mathrm{l}^{2}$. Hyperhomocysteinemia is a condition characterized by an abnormally high level of homocysteine in the blood conventionally described above $15 \mu \mathrm{mol} / 1^{3}$. Plasma homocysteine concentrations are frequently found to be elevated in cases of bad obstetric history but a causal relationship between these two has not been clearly demonstrated yet, hence the study was taken up with the aim of determining the correlation between plasma homocysteine level and bad obstetric history, and its relevance as a potential marker for predicting bad obstetric outcome.

Received: $1^{\text {st }}$ November 2020, Peer review completed: $10^{\text {th }}$ January 2021 , Accepted: $28^{\text {th }}$ January 2021.

Choudhury SS, Lokeshwari K, Das GC. Association between hyperhomocysteinemia and adverse obstetric outcome in patients with bad obstetric history. The New Indian Journal of OBGYN. 2021; 8(1): 19-22. 


\section{Methods}

The study was carried out in a tertiary care center from August 2012 to July 2013. Forty five pregnant patients with bad obstetric history with minimum 2 pregnancy losses were included in the study group and 20 normal pregnant women was taken as control group after obtaining informed consent following approval from institutional ethical committee. After taking detailed history and clinical examination, data collected in a structured proforma. Five milliliter of blood from anticubital vein was drawn and the sample with reagent was made to run in automated machine. A serum homocysteine level was measured by enzyme cycling method. Pregnant women with known diabetes, chronic hypertension, renal or liver disease, smoking, anaemia and patient on methotrexate, phenytoin, anticonvulsants, and carbamazepine were excluded. Data were tabulated in Microsoft excel sheet and analyzed with STATA. Students $T$ test was used to compare serum homocysteine level between case and controls. ANOVA test was used to find relation between causes and serum homocysteine levels. Chi square and Fischer's test were used to compare serum homocysteine levels and variables like age, period of gestations, systolic and diastolic blood pressure.

\section{Results}

A total number of 65 cases were taken. Out of which 45 cases had bad obstetric history and 20 cases was taken as control. The mean age in control group was 25.8 years and in the study group was 28.3 years. The mean period of gestation is 31 weeks in study group and 36 weeks in control group. Mean serum homocysteine level in control group was $9.23 \mu \mathrm{mol} / \mathrm{L} \pm 3.4$ with range 5.93-18.40 and that of $\mathrm{BOH}$ cases $25.91 \mu \mathrm{mol} / \mathrm{L}$ \pm 8.7 with a range of $7.53-50.80 \mu \mathrm{mol}(\mathrm{p}$ $<0.001)$. There were 22 cases of $\mathrm{BOH}$ with Table 4: Distribution of patients according

\begin{tabular}{l}
\hline Serum homocysteine \\
Within normal range $(<15 \mu \mathrm{mol} / \mathrm{L})$ \\
Elevated $>15 \mu \mathrm{mol} / \mathrm{L}$
\end{tabular}
Total mild and severe hypertension of pregnancy, 5 cases of APH (abruption), 11cases with multiple causes, 3 cases with GDM, 4 cases with congenital anomaly and 10 cases without significant causes. Range, mean and standard deviations are shown in table 1 . There is no relationship between serum
Table 2: Serum homocysteine level in normal pregnancy and BOH cases with no definite causes $(\mathbf{n}=10)$.

\begin{tabular}{llll}
\hline S homocysteine & Control & BOH with multiple causes & P value \\
\hline Mean $(\mu \mathrm{mol} / \mathrm{L})$ & 9.23 & 26.46 & $<0.0001$ \\
Standard deviation(SD) & 3.4 & 9.48 &
\end{tabular}

hyperhomocysteinemia and bad obstetric history with no definite cause. $\mathrm{P}$ value is less than 0.0001 which is extremely significant (table 2).

Multiple causes of $\mathrm{BOH}$ were taken into consideration when 3 or more than three factors are present in same pregnant women. The mean serum homocysteine level was

Table 3: Serum homocysteine levels in multiple causes $(n=11)$

S. homocysteine Control group $\quad$ BOH( multiple causes) $\quad$ P value (t test)

$\begin{array}{llll}\text { Mean }(\mu \mathrm{mol} / \mathrm{L}) & 9.23 & 26.6 & <0.001\end{array}$
SD $26.6 \mu \mathrm{mol} / \mathrm{L}, \mathrm{SD} 5.9$ compared to normal pregnancy which was $9.23 \mu \mathrm{mol} / \mathrm{L}, \mathrm{SD} 3.4$. There was a strong association between these two as $\mathrm{p}<0.001$ (table 3 ).

In the study group of $45 \mathrm{BOH}$ cases, $40(89 \%)$ cases had elevated level of homocysteine which is more than $15 \mu \mathrm{molL}$ and is statistically significant $(\mathrm{p}<0.001)$. Only $5(11 \%)$ cases had within normal range of less than $15 \mu \mathrm{mol} / \mathrm{L}$ in the study group. Whereas in control group 3(15\%) cases had elevated level and rest $17(85 \%)$ cases had normal levels of ing to serum homocysteine levels in cases of BOH and normal pregnancy

$\begin{array}{llllll}\text { Normal } & \text { Total } & \text { P value } & \text { RR } & \mathbf{9 5 \%} \text { CI }\end{array}$

\begin{tabular}{llllll} 
No(\%) & No(\%) & No(\%) & (Fischer's test) & & \\
\hline $5(11)$ & $17(85)$ & $22(34)$ & $<0.001$ & 0.2443 & $0.1126-0.5303$
\end{tabular}
$40(89) \quad 3(15) \quad 43(66)$ $45(100) \quad 20(100) \quad 65(100)$

homocysteine. In the 5 cases of $\mathrm{BOH}$ who had normal level of homocysteine there was no definite cause of bad obstetric history (table 4).

In the $\mathrm{BOH}$ group of diagnosed hypertension $12(54.5 \%)$ had mild and $10(45.5 \%)$ cases had severe form of disease 
had elevated homocysteine level which is highly significant $(\mathrm{p}<0.001)$ (table 5).

\begin{tabular}{llll}
\multicolumn{4}{l}{ Table 5: Comparison of serum homocysteine levels between mild and severe hypertension } \\
\hline Hypertension & No of cases (\%) & $\begin{array}{l}\text { S homocysteine } \\
(\boldsymbol{\mu m o l} / \mathbf{L})(\text { mean) }\end{array}$ & P value (unpaired t test) \\
\hline Mild & $12(54.5)$ & 25.6 & $<0.001$ \\
Severe & $10(45.5)$ & 29.9 & \\
Total & $22(100)$ & & \\
\hline
\end{tabular}

On comparison between control group with mild and severe hypertension, it was found that homocysteine is elevated in hypertension in pregnancy which was statistically significant (table 6). In control group, IUGR was seen in 2 cases and in study group, there were 14 cases with mean homocysteine in level without IUGR was $8.45 \mu \mathrm{mol} / \mathrm{L}$ and in presence of IUGR level was $26.7 \mu \mathrm{mol} / \mathrm{L}$ which was significant $(p<0.05)$. Mean level of homocysteine in women with term infant is $24.4 \mu \mathrm{mol} / \mathrm{L}, \mathrm{SD} 5.2$. In preterm and still birth cases its level is raised; 27.7,SD 8.4 and 26.5, SD 6.07 respectively which is also found to be significant $(\mathrm{p}<0.05)$. Caesarean section rate was $69 \%$ in $\mathrm{BOH}$ cases in comparison to $25 \%$ cases in control group which was also significant $(\mathrm{p}<0.001)$.

Table 6: Comparison of serum homocysteine level in between mild and severe hypertension and pregnancy without hypertension (HTN)

\begin{tabular}{lll}
\hline Categories & t value & P value \\
\hline Patients without hypertension (HTN) vs Mild HTN & 10.35 & $<0.001$ \\
Patients without HTN vs Severe HTN & 11.36 & $<0.001$ \\
\hline
\end{tabular}

hypertension. The mean level in mild and severe cases were $25.6 \pm 5.5$ and $29.5 \pm 6.3$ respectively which when compared to the level of it in normotensive women was found to be highly significant $(\mathrm{p}<0.001)$. There is a strong association between increased blood pressure and homocysteine levels $(\mathrm{r}=0.52$ and $\mathrm{p}<0.001)$. This suggests that homocysteine levels are directly correlated with severity of the hypertension in pregnancy. Laskowska $\mathrm{M}$ et al $2011^{6}$, Haque et al from Bangladesh ${ }^{7}$ demonstrated the relationship between hyperhomocysteinemia and preeclampsia while Hietela et al $2001^{8}$ refuted an association. It is possible that in preeclampsia, the elevated homocysteine level injures the vascular endothelium which contributes to the pathogenesis of preeclampsia. In addition vascular endothelium in pregnant women may be more sensitive to injury. Therefore elevation of this may lead to endothelial injury with subsequent activation of various factors that eventually results in preeclampsia.

\section{Discussion}

Increased serum homocysteine level has been identified as an independent factor of atherosclerosis, coronary heart disease and peripheral vascular disease. This risk is proposed to induce the modification of endothelial function which may involve both cytotoxic and oxidative stress mechanisms similar to those postulated to promote endothelial dysfunction in hypertensive disorders of pregnancy and fetal growth restrictions. Therefore hyperhomocysteinemia during pregnancy may contribute to these conditions.

In our study normal serum homocysteine level is considered as $5-15 \mu \mathrm{mol} / \mathrm{L}$ which is comparable to other studies by Holmes et al $2005^{2}$, Hogeveen et al ${ }^{3}$, Baksu et al $2006^{4}$.

In the study group, 22 cases of hypertension in pregnancy had a mean serum level of homocysteine of $27.7 \mu \mathrm{mol} / \mathrm{L}, \mathrm{SD}$ 6.4 and $9.23 \pm 3.4$ in normotensive cases; which was significant $(\mathrm{p}<0.001)$. This shows that decrease in homocysteine level which occur in normal pregnancy do not occur in preeclampsia due to some possible defect in the mechanism that usually decreases homocysteine in normal
During pregnancy an increased homocysteine level is a risk factor for recurrent spontaneous abortion, intrauterine fetal death and abruption placentae. It is not clear whether Hyperhomocysteinemia is a primary cause of these disease and abnormal outcomes or is just an epiphenomenon.

There is a significant association between preterm and intrauterine growth restriction (IUGR). Homocysteine is increased in presence of IUGR which is supported by the study from Bangladesh by Shirin F et al $2009^{9}(19.36 \pm 7.32$ with IUGR vs $9.85 \pm 4.17$ without IUGR, p <0.001). Our study showed $26.74 \pm 5.6$ in IUGR and $8.4 \pm 2.3$ without it and which is statistically significant, $\mathrm{p}<0.05$.

\section{Conclusions}

To conclude there is significant association between serum homocysteine levels and bad obstetric history and outcome compared to normal pregnant patients. Internationally accepted treatment for it is use of combination of folic acid, vitamin B12 and pyridoxine. Further studies are required to find out the etiology of hyperhomocysteinemia whether genetic or nutritional and the cause and effect relationship as level is increased in a 
The New Indian Journal of OBGYN. 2021 (July-December);8(1)

number of conditions of bad obstetric history and not very specific to a single conditions although a very strong relationship is seen in preeclampsia as well as its severity. But whether substitution with the standard medication for hyperhomocysteinemia can prevent their occurrence in pregnancy is still unanswered.

\section{Conflict of interest: None. Disclaimer: Nil.}

\section{References}

1. Renu Mishra, editor. Ian Donald's - Practical obstetric problem. $6^{\text {th }}$ edition. New Delhi : Wolters Kluwer India Pvt Ltd; 2010. p.96

2. Holmes VA, Wallace JM, Alexander HD, Gilmore WS, Bradbury I, Ward M, et al. Homocysteine is lower in the third trimester of pregnancy in women with enhanced folate status from continued folic acid supplementation. Clinical chemistry. 2005; 51(3): 629-34.

3. Hogeveen M, Blom HJ, Heijer den M. Maternal homocysteine and small for gestational age offspring: systematic review and meta- analysis. Am J Clin Nutr. 2012 Jan; 95(1):130-6

4. Baksu A, Taskın M, Goker N, Baksu B, Uluocak A. Plasma homocysteine in late pregnancies complicated with preeclampsia and in newborns. American journal of perinatology. 2006; 23(01):031-6

5. Makedos G, Papanicolaou A, Hitoglou A, Kalogiannidis I, Makedos A, Vrazioti V, et al. Homocysteine, folic acid and B12 serum levels in pregnancy complicated with preeclampsia. Archives of Gynecology and Obstetrics. 2007; 275(2):121-4.

6. Laskowska M. Homocysteine in pregnancies complicated by preeclampsia with and without IUGR: a comparison with normotensive pregnant women with isolated IUGR and healthy pregnant women. Open Journal of Obstetrics and Gynae. 2011, 1:191-6.

7. Haque MM, Bulbul T, Mahal M, Islam NA. Serum homocysteine in preeclampsia and Eclampsia. Bangladesh Med Res Counc Bull. 2008; 34: 10-20.

8. Hietala $R$, Turpeinen U, Laatikainen T. Serum homocysteine at 16 weeks and subsequent preeclampsia. Obstetrics \& Gynecology. 2001; 97(4): 527-9.

9. Shirin F, Mehdi T, Alam MM, Nath RK, Hoque MM. Effect of Gestational Homocystein on Fetal Growth in Bangladeshi Women. Ibrahim Medical College Journal. 2009; 3(1):13-6.

\section{Saswati Sanyal Choudhury ${ }^{1}$, Lokeshwari ${ }^{2}$, Gokul Chandra Das ${ }^{3}$ \\ ${ }^{1}$ Professor, Department of Obstetrics and Gynaecology, Gauhati Medical College. Guwahati, Assam, India; ${ }^{2}$ Associate Professor, Basaveshwara Medical College, Chitradurga, Karnataka, India, India; \\ ${ }^{3}$ Ex Prof \& HOD, Department of Obstetrics and Gynaecology, Gauhati Medical College, Guwahati, Assam, India.}

